TITLE:

\title{
A SUPPOSITION ON THE SYSTEMATIC POSITION OF NAMIELLA BISTIGMATA C. MONNIOT \& F. MONNIOT
}

\author{
$\operatorname{AUTHOR}(\mathrm{S})$ :
}

Tokioka, Takasi

\section{CITATION:}

Tokioka, Takasi. A SUPPOSITION ON THE SYSTEMATIC POSITION OF NAMIELLA BISTIGMATA C. MONNIOT \& F. MONNIOT. PUBLICATIONS OF THE SETO MARINE BIOLOGICAL LABORATORY 1968, 16(4): 291-294

\section{ISSUE DATE:}

1968-12-27

URL:

http://hdl.handle.net/2433/175547

RIGHT: 


\title{
A SUPPOSITION ON THE SYSTEMATIC POSITION OF NAMIELLA BIS TIGMATA C. MONNIOT \& F. MONNIOT ${ }^{1)}$
}

\author{
TAKASI TOKIOKA
}

Seto Marine Biological Laboratory

Recently Claude Monniot and Françoise Monniot of the Laboratory of General Ecology of the National Museum of Natural History, Brunoy, France described six new deep sea ascidians collected by the Atlantis II from the area of the North Atlantic, $38^{\circ} 16^{\prime}-39^{\circ} 46.5^{\prime} \mathrm{N}$ and $70^{\circ} 06^{\prime}-71^{\circ} 47^{\prime} \mathrm{W}$ (Monniot \& Monniot, 1968). Two of those new forms belong respectively to different new genera: they are Namiella bistigmata and Gasterascidia sandersi.

Studying closely the descriptions of the two species seen in the journal just accessioned at the laboratory library, first I was much surprised by so thorough sorting of the collected material of the Atlantis II and secondly much impressed by the authors' wonderful skillfulness of dissecting solitary ascidians as small as $2-5 \mathrm{~mm}$ in body length.

The proper systematic position of Gasterascidia sandersi which is completely devoid of the branchial sac seemed to remain beyond the reach of my knowledge. As to Namiella bistigmata collected from the 1470-1330 m deep, however, I thought of another systematic position quite different from what proposed by the authors. This was never intended to find out for this species any other position which might be nearer to the judgement by the God's eye than the already given position is, but to have a chance for reflection for myself on the distinction and relation between Phlebobranchiata and Stolidobranchiata.

Namiella bistigmata was defined on the single small, $2.5 \mathrm{~mm}$, specimen which was in a condition permitting the sufficient study of the whole organization. According to the authors' description and text-figures-

The transparent body is roundish and flattened laterally, and attached to the substratum by (1) a tuft of fine fragile rooty protuberances. The branchial aperture is situated near the middle of the dorsal side of the body, sessile and (2) surrounded by four small prominences, while the atrial opens at the surnmit of the indistinct prominence at the distal end of the body. The test is very thin and flexible. The main part of the body musculature consists of transverse muscles running between both apertures. The tentacles are about ten, of several orders: (3) two of them situated on both sides of the dorsomedian line are ramified, branches in one order. A narrow velum in front of the tentacular ring. The ciliated groove is a transverse slit. (4) The dorsal lamina consists of two smooth membranes.

(5) The branchial sac is not plicated. (6) There are 5 inner longitudinal vessels, without any supporting prominences, and 7 transverse rows of stigmata on one side; while 6 vessels and 8 stigmatal rows on the other side.

1) Contributions from the Seto Marine Biological Laboratory, No. 497.

Publ. Seto Mar. Biol. Lab., XVI (4), 291-294, 1968. (Article 21) 
Stigmata are arranged as two stigmata form together an infundibulum and a series of infundibula thus formed are situated under each inner longitudinal vessel. Stigmata are short and infundibula contain respectively only a single spire of each stigma at the maximum. Two adjoining transverse rows of infundibula form a couple and external ends of four stigmata of adjoining four infundibula converge on the transverse vessel defined indistinctly between the two transuerse infundibular rows. Stigmata are bridged irregularly by fine parastigmatic vessels.

The voluminous alimentary canal is (7) situated on the left side of the branchial sac. The oesophagus is thin, elongate, and curved. The gastric region is large and covered (at least on the right side) (8) with three glandular cushions diminishing the size posteriorly. The intestine is divided into two or three portions by constrictions. The second intestinal loop is distinct, its axis passing through the cardiac end of the gastric region. The anal margin is furnished with three finger-shaped lobules. A blood vessel connects the anus to the gastric region, across the intestine and passing over the male and female gonads.

The gonad is situated (9) in the (first) intestinal loop. The testis occupies the bottom of the loop, consists of four lobated follicles, and opens at the male genital aperture situated at the centre of the intestinal loop. The ovary is situated under the testis and extends distally to the oviduct which proceeds along the gastric region, across the intestine, then parallel to the rectum, and terminates near the anus, but (10) far apart from the male genital aperture.

(11) The excrelory system consists of many accumulating vesicles. Though the vesicles are distributed on the whole inner suface of the mantle, they are found especially densely on the ovary surface and on both sides of the branchial siphon. Each accumulating vesicle consists of a cell with a very large spherical vacuole and the excentric nucleus dislocated by the large vacuole. A thin peduncular protuberance issues from the cell side opposite the nucleus and leads to an irregularly shaped cell having the dense cytoplasm and the big nucleus at the centre. A single of such irregularly shaped cells can be united with one to several accumulating cells.

The authors admitted by themselves some juvenile characters of the specimen such as the ovary containing only small ovocytes and the existence of a fragment of protostigma in the process of division, but expected no anatomical alteration in its further growth. And for its peculiar appearances of the alimentary canal, the excretory system, separately opening genital apertures, and strange structure of the branchial sac, they proposed a new genus for the specimen. And the established genus was assigned by the authors provisionally to the family Ascidiidae after the characteristics of Cionidae, Corellidae, Agnesiidae, and Ascidiidae of the order Phlebobranchiata were compared with one another. This was made for the situation of the alimentary canal on the left side of the branchial sac, the mebranous dorsal lamina, and the existence of the inner longitudinal vessels.

I agree with the authors that no further significant anatomical modifications might occur on the form under consideration, except for some numerical differences or alterations in some measurements. However, reading carefully the authors' description and examining text-figures closely, I thought of immediately the family Molgulidae of the order Stolidobranchiata in place of Ascidiidae. This is very important, because Phlebobranchiata belongs to Enterogona, while Stolidobranchiata is included in Pleurogona. The situations are separated from each other so remotely superficially. This was the reason why I started to check exactly respective features of Namiella bistigmata.

The existence of inner longitudinal vessels is common to Phlebobranchiata and Stolidobranchiata, but the absence of the branchial plications (5) does not confine that 
form to Phlebobranchiata, because some social or compound styelids and some molgulids are also devoid of branchial plications. In Phlebobranchiata, the inner longitudinal vessels are raised on supporting papillae, while in Stolidobranchiata the vessels may in some forms be raised on papillae which are low but never so prominent as supporting papillae in Phlebobranchiata. In this respect (6), N. bistigmata stands on the side of Stolidobranchiata. The authors considered that the ramified tentacles might be a kind of malformation (p. 9), because the ramification of tentacles has never been noted in any form throughout Enterogona. On the contrary, the existence of branched tentacles (3) is a feature generally found in families Pyuridae and Molgulidae of Stolidobranchiata. The situation of the alimentary canal on the left side of the branchial sac (7) is common to Stolidobranchiata and Phlebobranchiata excepting Corellidae of the latter. In Enterogona, the neural gland forms generally the subneural gland ventral to the dorsal ganglion, while in Stolidobranchiata the neural gland is represented by the epineural gland dorsal to the ganglion. Therefore, it is very desirable that a further check on this point is made on the specimen.

In addition to the above-mentioned fundamental differences between Phlebobranchiata and Stolidobranchiata, the following features of $N$. bistigmata seem to show some resemblances to the family Molgulidae. The existence of rooty protuberances to fix the animal to the substratum (1) is a general feature for Molgulidae, but this has never been seen in families Gionidae and Ascidiidae. It is true that the dorsal lamina in Ascidiidae is membranous. The lamina is, however, not smooth thoroughly, but distinctly ribbed at the levels corresponding to respective transverse vessels and the free margin of the lamina is often, at least partly, furnished with prominences at the end of each rib. The essential feature of this type of dorsal lamina may be seen in Perophora and Ecteinascidia which may safely be accepted as primitive ascidiids. On the other hand, the existence of the really smooth dorsal lamina is a characteristic of families Botryllidae, Styelidae, Microcosmus of Pyuridae, and Molgulidae. The existence of two membranes partially along the site of the dorsal lamina (4) is noted in Eugyra and its allies of Molgulidae. The peculiar arrangement of stigmata of $N$. bistigmata (6) is not strange for Eugyra and its allies. The existence of four prominences (2) alluding the four lobes around the branchial aperture is exceptional for Ascidiidae, but this is not uncommon for some molgulids. It is not impossible that three glandular cushions (8) on the gastric region of $N$. bistigmata show a rudimentary state of the hepatic gland or hepatic plications of molgulids. The situation of the left gonad in the intestinal loop (9) is a general feature common to Pyuridae and Eugyra and its allies of Molgulidae. The wide separation of the male genital aperture from the female one (10) is not rare in Molgulidae. The excretory system consisting of accumulating vesicles distributed over the mantle and gonad surfaces (11) differs distinctly from the system found in Molgulidae in which it forms a distinct renal sac. The formation of the renal sac may be, however, rather indistinct in some molgulid. Hartmeyeria has distinctly an elongate renal sac on the right side of the body and thus it should be in- 
cluded in Molgulidae as I proposed far ago (1953), though the wall of the sac is extremely delicate so that it might be overlooked very easily. I fear that the proper position of Hartmeyeria might not be accepted by those who have not yet confirmed the existence of the renal sac by their own observations. Anyhow, the state found in Hartmeyeria shows an earlier stage of the formation of renal sac in Molgulidae, and the state of excretory system in $N$. bistigmata might show another earlier stage of the development of renal sac. However, it is very important to notice that in many species of Ascidia "numerous minute, closed, renal vesicles containing concretions are present in the vicinity of the digestive organs" (VAN NAME 1945, p. 175).

Throughout the discussions mentioned above, $N$. bistigmata can be included very easily in Molgulidae, if the feature of the excretory system is put aside. In Molgulidae, the morphology of Eugyra and that of young Bostrichobranchus resemble most closely the structure of $N$. bistigmata. It is supposed that the ultimate decision of the systematic position of $N$. bistigmata will be made on (1) the actual situation of the neural gland and (2) whether the excretory system shows a rudimentary state or some earlier developmental stage of renal sac or it represents truely a special adult feature.

(A) If the neural gland is situated dorsal to the dorsal ganglion and the former is the case as to the excretory system, then $N$. bistigmata can be treated as a species of the genus Eugyra, as the vertical range of E. glutinans (MOELLER) is very wide to reach 1805 m (HARTMEYer 1923, p. 25), or as a form of a genus closely allied to that genus.

(B) If the neural gland represents the epineural gland and the latter is the case as to the excretory system, then $N$. bistigmata must be treated as a species of a very distinctive genus probably in the family Molgulidae.

(C) If the neural gland is situated ventral to the dorsal ganglion, $N$. bistigmata will become a very important form intermediate between Phlebobranchiata and Stolidobranchiata. Then, the family Molgulidae will be united with the family Pyuridae through Hartmeyeria and Microcosmus on one hand and with families Agnesiidae and Ascidiidae through $N$. bistigmata on the other hand. It will inevitably become necessary to establish a new family to hold $N$. bistigmata, and the distinction between Phlebobranchiata and Stolidobranchiata will become somewhat obscure, although these will make the taxonomical system of ascidians more complicated.

\section{REFERENCES}

Hartmeyer, R. (1923): Ascidiacea. In Danish Ingolf-Expedition, Vol. 2, Part 6, 368 pp., 35 textfigs., 1 pl., 1 map.

Monnot, C. et F. Monniot (1968): Les ascidies de grandes profondeurs recoltees par le naive óceanographique americain Átiantis İ̄. Bull. Inst. Oceanogr. Monaco, Vol. 67, No. 1379, 48 pp., 21 text-figs.

Tоктока, T. (1953): Ascidians of Sagami Bay. Tokyo.

VAN NAmE, W.G. (1945): The North and South American ascidians. Bull. American Mus. Nat. Hist., Vol 84. 